\title{
Pododermatitis por contacto en pollos de engorde bajo diferentes condiciones de cama
}

\author{
Villamañe, R. ${ }^{1}$; Rodríguez, E.; Rebagliati, J.E. ${ }^{2}$; Yuño, M. ${ }^{3}$ \\ ${ }^{1}$ Veterinario, actividad privada. ${ }^{2}$ SENASA, Fac. Cs. Veterinarias, UNCPBA. \\ ${ }^{3}$ Campus Universitario, Tandil. Buenos Aires, Argentina. \\ E-mail: myunio@vet.unicen.edu.ar
}

\begin{abstract}
Resumen
Villamañe, R.; Rodríguez, E.; Rebagliati, J.E.; Yuño, M. Pododermatitis por contacto en pollos de engorde bajo diferentes condiciones de cama. Rev. Vet. 31: 1, 66-68, 2020. La dermatitis de contacto es una inflamación cutánea que afecta la superficie de la planta del pie, la piel de la articulación del tarso y además -en casos severos- el área del hueso de la quilla pectoral. Es una patología originada por múltiples causas, en la que están involucrados el medio ambiente, la nutrición y la integridad intestinal. Su importancia radica en que afecta el bienestar animal y genera pérdidas económicas por decomisos en la faena. El objetivo de este trabajo fue evaluar las lesiones plantares, en pollos Cobb 500 de 40 días de edad alojados en dos sistemas de producción: galpón con cama nueva $(\mathrm{GCN})$ y galpón con cama utilizada en cuatro períodos (GCU). Se observó que el 77\% de los animales alojados en GCN no presentaron lesiones, y que el 23\% restante presentó lesiones de grado 1 ó 2; mientras que $28 \%$ de los animales alojados en GCU no presentaron lesiones y el $72 \%$ presentaron lesiones de grado 1 ó 2 . Los porcentajes de lesiones hallados en ambos grupos fue significativamente diferente $(p<0,001)$, señalando que los animales que se encuentran en la cama usada tienen 8,6 veces más probabilidades de presentar lesiones de mayor grado que los alojados sobre cama nueva.
\end{abstract}

Palabras clave: pollos, lesiones dérmicas podales, camas nuevas y usadas, decomisos.

\begin{abstract}
Villamañe, R.; Rodríguez, E.; Rebagliati, J.E.; Yuño, M. Footpad dermatitis by contact in poultry in different litter conditions. Rev. Vet. 31: 1, 66-68, 2020. Footpad dermatitis is an inflammation of the skin that affects the surface of the sole of the foot, the skin of the tarsal joint and, in severe cases, the bone of the pectoral keel. It is a multicausal pathology in which the environment, nutrition and intestinal integrity are involved. It affects animal welfare and generates economic losses due to confiscation during slaughtering. The objective of this work was to evaluate the plantar lesions in 40-day-old Cobb 500 chickens, housed in two production systems: new litter (NL) and litter used in four periods (UL). It was observed that $77 \%$ of the animals housed in NL did not present lesions, and 23\% presented lesions of grade 1 or 2 . On the other hand, $28 \%$ of the animals housed in UL did not present lesions, while $72 \%$ presented lesions of grade 1 or 2 . The percentages of lesions found in both groups were significantly different $(p<0.001)$, pointing out that animals located on UL are 8.6 times more likely to present lesions of greater degree than those housed on a new bed.
\end{abstract}

Key words: chickens, dermal paw lesions, new and used litters, losses.

\section{INTRODUCCIÓN}

La pododermatitis por contacto es una inflamación de la piel, que en los pollos de engorde afecta principalmente la superficie de los metatarsos, la articulación del tarso, el cojinete plantar y con menor frecuencia el área pectoral. Esta patología se presenta en las aves de producción alojadas en el interior de galpones, con diferentes tipos de sustrato para cama.

En la Unión Europea fue observada la presentación de esta patología en el $40 \%$ de los animales, con mayor

Recibido: agosto 2019 / Aceptado: noviembre 2019 frecuencia en meses estivales, lo cual motivó que en el año 2002 se haya iniciado un monitoreo de la pododermatitis en la industria avícola para mejorar las condiciones de bienestar de los animales ${ }^{6}$.

Las lesiones comienzan con una erosión superficial de la epidermis y rápidamente evolucionan a úlceras con necrosis, presencia de edema e inflamación en el tejido subcutáneo, así como también aumento del espesor de la capa de queratina ${ }^{4,5}$. Posteriormente, las lesiones suelen contaminarse con agentes fúngicos $\mathrm{o}$ bacterianos, especialmente estafilococos ${ }^{9}$.

Las causas primarias de la pododermatitis de contacto no son infecciosas sino que están vinculadas a la 
mala calidad de la cama por exceso de humedad. Generalmente ocurren por el inadecuado manejo del medio ambiente e implementos (bebederos, sistemas de fogging y ventilación) ${ }^{5,7}$.

En tales condiciones, los niveles de amoníaco se elevan a concentraciones perjudiciales, dado que la temperatura debajo de la capa superficial y el $\mathrm{pH}$ de la cama aumentan, creando un medio ambiente ideal para las bacterias sintetizadoras de amonio, presentes en la cama por su alto contenido de humedad.

El tipo de piso de los galpones, habitualmente de tierra compactada o concreto, no afecta la humedad de la cama ${ }^{1}$, sin embargo, no todos los materiales utilizados como cama tienen similar capacidad para absorber la humedad ${ }^{4}$. Se ha observado que pollos alojados en un ambiente con cama húmeda y afectados con pododermatitis, revirtieron esta condición luego de quince días de estar albergados en un ambiente seco e incluso aumentaron su ganancia de peso ${ }^{5}$.

Otros factores asociados a la pododermatitis son la presencia de materia fecal en exceso o muy acuosa, que la cama no pueda absorber. Ambas situaciones se presentan con alta densidad de animales, también en raciones con insumos que generen aumento del consumo de agua ${ }^{14}$, o bien como consecuencia de problemas sanitarios que afecten la integridad intestinal como coccidiosis, micotoxinas o enteritis bacterianas.

La pododermatitis implica para las aves dolor constante que afecta su movilidad, dificultando el acceso al alimento y al agua ${ }^{2,4}$. En consecuencia, la problemática establecida puede ser analizada desde distintos aspectos, ya que están comprometidos el bienestar animal y los parámetros productivos, con las consecuentes pérdidas económicas por decomisos en planta de faena.

Los tarsos y metatarsos, habitualmente conocidos como "garras", son comercializados en el mercado asiático y representan el $8 \%$ de las exportaciones de productos y subproductos avícolas ${ }^{13}$. Las lesiones producidas por la pododermatitis ocasionan una depreciación de valor e incluso la imposibilidad de exportar el producto.

El objetivo de este trabajo fue evaluar las lesiones podales en pollos de engorde alojados en galpones con diferente calidad de cama.

\section{MATERIAL Y MÉTODOS}

El ensayo fue realizado en dos galpones, pertenecientes a una granja industrial, con igual estructura edilicia e implementos: $100 \mathrm{~m}$ de largo por $15 \mathrm{~m}$ de ancho, sistemas de ventilación natural por cortinas laterales manuales, con forzadores de aire, comederos comunitarios de tolva automática y bebederos tipo niple con bombas automáticas.

En ambos galpones el sustrato de cama fue cáscara de arroz. Un galpón fue acondicionado con cama nueva (GCN) y el otro galpón con cama utilizada en cuatro períodos sucesivos de 43 días cada uno (GCU).

En el GCU la cama fue tratada con un roto-cultivador para removerla, airearla y disminuir la compacta- ción. Además, se renovó una proporción de cama nueva sólo en el sector de recepción de los pollitos, en su primer día de vida. Durante el ensayo una muestra de la cama fue obtenida aplicando el método lineal oscilante ${ }^{3}$, recorriendo el galpón en zig-zag (secciones: centro y laterales derecho e izquierdo).

El material de cama recolectado en cada sección (aproximadamente $5 \mathrm{~kg}$ en cada una) fue homogeneizado, extrayendo una sub-muestra de $2 \mathrm{~kg}$ para evaluar el porcentaje de humedad por secado en estufa a $105^{\circ} \mathrm{C}$ durante 2 horas.

Los pollos, de línea genética Cobb 500, provinieron de una planta de incubación industrial y se alojaron en los galpones el primer día de vida, con una densidad de $30 \mathrm{~kg} / \mathrm{m}^{2}$ a edad de faena. La presencia de lesiones plantares fue realizada al día 40 de edad en una muestra de 500 animales por galpón, el cual fue dividido en tres tercios con polietileno de $15 \mathrm{~m}$ de largo x $0,60 \mathrm{~m}$ de alto, recorriendo cada uno en forma de guarda griega levantando un animal a cada paso hasta completar 166 pollos en los dos primeros tercios y 168 pollos en el último tercio.

Las lesiones plantares fueron observadas y clasificadas en categorías ${ }^{6}: 0=\sin$ lesiones; $1=$ lesión leve; decoloración de la almohadilla plantar, lesiones superficiales, papilas oscuras e hiperqueratosis; $2=$ lesión severa; epidermis afectada con hemorragias, úlceras, cicatrices o almohadillas plantares inflamadas.

Por lo tanto, la variable lesiones plantares fue analizada como una variable categórica ordinal $(0,1$ y 2$)$, evaluando el efecto del tratamiento y estimando el riesgo de presentación de lesiones. El análisis estadístico fue realizado utilizando el procedimiento Proc. Genmod. Statistical Análisis Systems, version 9.3, SAS ${ }^{15}$.

\section{RESULTADOS Y DISCUSIÓN}

Los resultados observados (Tabla 1) indican que en el GCN la mayoría de los pollos no presentaron lesiones, mientras que en el GCU las lesiones de grado 1 y 2 se observaron en el $72 \%$ de los pollos. Ambos grupos tuvieron diferencias estadísticamente significativas $(p<0,001)$, demostrando que los animales que se encontraban en la cama usada tenían 8,6 veces más oportunidades de presentar lesiones de mayor grado que los animales alojados sobre cama nueva, $\mathrm{OR}=8,6$ LI $95 \%=5,4$ - LS $95 \%=13,6$.

Tabla 1. Frecuencia y grado de lesiones (\%), según tipo de cama.

\begin{tabular}{lcccc}
\hline cama & grado 0 & grado 1 & grado 2 & total \\
\hline nueva (GCN) & 3788 & 102 & 10 & 500 \\
usada (GCU) & $17,6 \%$ & $20,4 \%$ & $2 \%$ & \\
total & $28 \%$ & 315 & 45 & 500 \\
\hline
\end{tabular}

GCN: galpón con cama nueva; GCU: galpón con cama utilizada en cuatro períodos. 
Los efectos logrados fueron similares a los obtenidos por otros investigadores, quienes observaron que la presentación de pododermatitis aumenta utilizando camas de cuatro crianzas ${ }^{2}$.

El resultado del análisis de humedad de la cama fue $30,72 \%$ para ambos, GCN y GCU; resultando similares a los obtenidos por otros autores ${ }^{5,8,16}$, quienes observaron un incremento de pododermatitis y mayor contaminación con patógenos por uso de camas con elevada humedad. La recomendación para la línea Cobb 500 es utilizar camas con humedad inferior al $36 \%{ }^{10}$.

Si bien la cama usada tiene un costo $50 \%$ inferior a la cama nueva ${ }^{12}$, las desventajas radican en que se compacta en la superficie por exceso de humedad (>36\%); pérdida de friabilidad del material por sucesivos ciclos de humedad y secado ${ }^{11}$, factores que tienen como consecuencia la presentación de pododermatitis.

Los resultados obtenidos permiten inferir que en los pollos, la pododermatitis puede ser utilizada como indicador de deterioro de la calidad de la cama y falla del bienestar animal.

\section{REFERENCIAS}

1. Abreu VM, Abreu PG, Jaenisch FR, Coldebella A, Paiva DP. 2011. Effect of floor type (dirt or concrete) on litter. Braz J Poultr Sci 7: 127-137.

2. Balaguera R, Córdoba GM. 2014. Análisis histológico de lesiones podales de pollos comerciales en la planta de sacrificio de pollo Olympico S.A.(Colombia), Nova 12: 187-197.

3. Barrios MA. 2009. Manejo de la cama avícola, descuidos que cuestan caro. http://www.avesyporcinos.com.ar/nota. php?id.

4. Bilgili SF et al. 2009. Influence of bedding material on footpad dermatitis in broiler chickens. Appl Poult Res 18: 583-589.
5. Bradshaw RH, Kirkden RD, Broom DM. 2002. A review of the aetiology and pathology of leg weakness in broilers in relation to welfare. Avian Poultr Biol Rev 13: 45-103.

6. Dejong I, Harn J. 2012. Prácticas de manejo para reducir la podermatitis en el pollo de engorde. Aviagen, $28 \mathrm{p}$.

7. Dejong I, Harn IJ, Hindle VA, Lourens A. 2012. Footpad dermatitis in dutch broiler flocks. Prevalence and factors of influence. Poultr Sci 91: 1569-1574.

8. Dejong I, Veldkamp T, Harn J. 2013. Management tools to reduce footpad dermatitis in broilers. $19^{\text {th }}$ European Symposium on Poultry Nutrition, Potsdam (Germany), 78-83.

9. Chaudhary $\mathbf{S}$ et al. Prevalence of pododermatitis caused by Staphylococcus aureus in poultry birds of Jammu. Intern J Livestock Res 8: 192-195.

10. Cobbvantress. 2019. Guía de manejo del pollo de engorde Cobb. https: //www.cobb-vantres.com.

11. Medeiros R et al. 2008. A adicao de diferentes productos químicos e o efeito da umidade na volatilizacao de amonia em cama de frango. Ciênc Rur Sta María 38: 2321-2326.

12. Miguez A, Fernández H, Zonco MC. 2014.Manejo y rendimiento de camas en pollos de engorde. Tesina de grado. https://opac.biblio.unicen.edu.ar/opacunicen/.

13. Ministerio de Agricultura Ganadería y Pesca de la Nación. 2013. Boletín avicola, https://www.agroindustria.gob.ar/sitio/areas/aves/informes/boletines/ archivos $/ / 000$ datos\%20Hist\%C3\%B3ricos $/ 000070$ Nro70\%20Diciem\%20\%202013.pdf.

14. Nagaraj M, Wilson CA, Hess JB, Bilgili, SF. 2007. Effect of high protein and all vegetables diet son the incidence and severity of pododermatitis in broiler chickens. $J$ Appl Poul. Res 16: 304-312.

15. Statistical Analysis Systems, 2011. Version 9.3; SAS, Institute Inc., Cary, NC, USA.

16. Turner BJ. 2008. Manejo y reuso de cama. Tratamientos para prevención de enfermedades. www.aviagen.com. 